\title{
Institutional Innovations for Management and Commercialisation of Fishery Technologies in India - A Case Study
}

Razia Mohamed Arakkal ${ }^{1}$, Manoj P. Samuel ${ }^{1, *}$, George Ninan $^{1}$, Ravishankar C. Nagarajarao ${ }^{1}$

${ }^{1}$ ICAR- Central Institute of Fisheries Technology, Kochi, Kerala- 682029, India

${ }^{*}$ Corresponding author email:

manojpsamuel@gmail.com

Received date: 14 Jan 2020

Published date: 31 Dec 2020

\section{How to cite:}

Arakkal, R.M., Samuel, M.P., Ninan, G. \& Nagarajarao, R.C. (2020). Institutional Innovations for Management and Commercialisation of Fishery Technologies in India - A Case Study. Journal of Research Management \& Governance, 3(1), 18-35. Retrieved from https:// ejournal.um.edu.my/index.php/ JRMG/article/view/21789

DOI:

https://doi.org/10.22452/ jrmg.vol3no1.2

\begin{abstract}
India is a country with unique market dynamics and high entrepreneurial spirit. During recent years, the country's industry sector is dominated by innovation led business enterprises that are found to achieve high profits within a short span of time. This paradigm shift is mainly influenced by the significant role played by technology-based business incubation support systems and expert mentorship programmes. It is observed that start-up companies emerging from these incubators are becoming machines of rapid and tremendous growth. In support of this growing trend and with the aim of laying the foundation for innovation-based businesses and knowledge-driven economy in agricultural sector, the Indian Council of Agricultural Research (ICAR) - an apex public research organization in India, established a network of Agri-business incubation ( $A B I$ ) Centres linking its R\&D Institutes across the country. Through this initiative ICAR brought into place novel policies and programmes, to maximize technology commercialization, establish public private partnerships and handhold entrepreneurs. This paper portrait the activities of such an $A B I$ Centre attached to ICAR - Central Institute of Fisheries Technology, and presents an overview of the new systems of business incubation and support services to entrepreneurs. The clients registered at the $A B I$ Centre are given necessary guidance to choose a suitable technology with the help of Technology Readiness Levels (TRL) and given an opportunity to commence business operations using the semi-commercial pilot plant facilities attached to the institute. A case study of a client who adopted the ICAR-CIFT technology for 'Hybrid Solar Dryer' is also included in this paper.
\end{abstract}

Keywords: Agri-business; Entrepreneurship; Innovation; Fisheries; Research; Technology; Commercialisation 


\section{Introduction}

In India, agriculture research and agrarian economy has evolved over the last decade in a much more dynamic and innovative manner. In the changing socio-economic context and global market-driven economy, innovation is increasingly recognized as a driving factor that enhances business competitiveness. Technologically empowered businesses are found to be key players in the industry and most profit-making entities. The country is giving much attention to promoting Agri-based innovations that promise solutions to many of the current challenges faced by the sector. The National Agricultural Research and Education System (NARES) is a major stakeholder in agricultural research, which focuses on technology creation and its delivery to other stakeholders such as farmers, producer groups, retailers, corporations, civil societies and private players (Srinivas, 2018). NARES has always been responsive to the current needs of the stakeholders and maintains a more pluralistic innovation system addressing the needs of the consumers. The successful adoption of the technologies arising out of this system has significantly enhanced the incomes of the stakeholders including farmers.

The Indian Council of Agricultural Research (ICAR) is the apex public research organization which has been playing a key role in the innovation processes concerning agriculture in the NARES system. ICAR harnesses and synergizes the innovative research mechanism and business support ecosystem by utilizing the efficient scientific manpower and vast resources. This ensures the efficient utilization of innovative technologies, processes and products, thus leading to significant enhancement of the agrieconomic system as a whole. As part of this drive and to ensure dissemination/commercialization of its research outcomes and knowledge base, ICAR created an institutional mechanism connecting its 101 Research \& Development (R\&D) institutes, serving diversified fields like fisheries, horticulture, crop science, animal science and natural resource management. This chain of Agri Business Incubation (ABI) centres across India, became one of the successful initiatives of ICAR, where scientific knowledge is translated into innovation led commercial ventures developing market-driven products (ICAR, 2006). Taking into consideration the vast potential of the fisheries sector and the needs to promote technoentrepreneurship among fishermen community, ICAR started India's first fisheries Business Incubation Centre at ICAR-Central Institute of Fisheries Technology, Kochi, Kerala, for establishing sustainable businesses in fisheries and allied agricultural fields. Numerous technologies have been transferred by the Institute through this incubation mechanism and one of them is the technology for Hybrid Solar Dryers. The technology achieved so much popularity due to its economic feasibility and easy adoption by fishers, micro, small and medium scale entrepreneurs and women Self Help Groups (SHG). This technology goes in tandem with the flagship programmes of the Government of India such as Atma Nirbhar Bharat, Swatch Bharath and National Mission for Green India. It effectively contributes to the country's commitment in reducing carbon emission, and aids in improving the livelihood of fishermen community by assuring returns even during off-season period.

\section{Start-up Policies in India}

In India, agriculture and its allied sectors, is the prime source of livelihood for the majority of the population. $70 \%$ of its rural households still depend mainly on agriculture and allied activities, which includes $82 \%$ of small and marginal farmers (FAO, 2019). India's economic growth has accelerated considerably in 2019 owing to the improved performance in both industry and services. India is the world's 3rd largest by purchasing power parity (PPP) and 6th largest economy by nominal GDP. The 
country ranks 139th in per capita GDP (nominal) with $\$ 2,134$ and 122 nd in per capita GDP (PPP) with $\$ 7,783$ as of 2018 (World Bank data). Agriculture sector employed 59\% of the country's total workforce in 2016 and contributed to 23\% of GDP (OECD, 2018). In the last two decades, powered by the government policies and strong engagement of the industry and institutions, Indian agriculture sector has rapidly evolved into agribusiness in terms of innovations, technology adoption, approach and structure.

With the aim of building a strong ecosystem to promote startups and entrepreneurs across the country, Government of India launched the Startup India Policy in January 2016, supported by other initiatives like Skill India, Start Up India, Stand Up India, MUDRA, ACABC scheme and Udaan (ICFA, 2019) to help budding entrepreneurs start and scale new ventures. These schemes have significantly addressed the crucial skills gaps in the employment sector and are aiming to equip citizens with industrial training and skills. Under the Skill India Mission, nearly ten million people, particularly youth, are trained under various programmes every year (NSDC,2020).

\section{Role of ICAR in promoting entrepreneurship in agricultural sector}

The processes of technology transfer from academic institutions to industry have emerged during the last two decades following the "Bayh-Dole Act of 1980", an amendment to the patent code of the United States. It paved the way to claiming ownership in intellectual property on research funded by the U.S. Government. Soon this led to similar initiatives in India. In the Indian NARES, ICAR has taken the stewardship of technology commercialization through the promulgation of IP and technology commercialization policy. Being a public funded research organization, ICAR often faces difficulty in categorizing its technologies into public and proprietary technologies as the ultimate stakeholders are poor and marginal farmers and fishermen. Big industrial houses and investors are generally reluctant to invest in agriculture and allied technologies considering its low rate of returns and high risk involved. Moreover, a few national/multinational companies are the major players in the agricultural input-output trading sector, making it a more monopolistic competition. However, to overcome these issues and to fetch both domestic as well as international seekers of technology, ICAR has devised the above said three-tier system of business incubation and established a global company like Agrinnovate India Ltd.

Constitution of Intellectual Property and Technology Management (IPTM) Division at Headquarters, and integration of aspects of intellectual property rights (IPR) in the technology management of R\&D institutions was the initial step taken by ICAR (ICAR, 2014). They formulated the guidelines for Intellectual Property Management and Technology, and created a decentralized 3-tier IPR and technology management mechanism. The implementation of these guidelines helped in the systematic organization of IPR filings and commercialization intellectual assets developed by its research institutes catering to diverse and specialized fields of agriculture (ICAR, 2018).

The business incubation drive started by ICAR in 2009 through the World Bank funded projects, was specially designed for the benefit of Indian agricultural sector. It successfully promoted agribusiness programmes, reinforcing public-private partnerships in agriculture. Through these partnerships and technology transfers, ICAR was able to ensure the successful dissemination of valuable and diversified ICAR knowledge base to the end users. There are eight research institutes specialized in the field of 
Fisheries under ICAR, with a large number of technologies ranging from harvest to post-harvest. ICAR adopted the concept of techno entrepreneurship to enable public-private partnerships benefiting larger sections of the society and utilize the innovations to compete in the global market. It is pertinent that the research outcomes are transformed into marketable products and services that can be leveraged to generate revenue and enhance R\&D pursuits in ICAR. The Council implemented a scheme titled National Agriculture Innovation Fund (NAIF) in 2017, which essentially has three main components to promote innovation, incubation and sustainability (NAARM, 2019).

Innovation led entrepreneurship needs R\&D backup, access to scientific resources, support functions and mentorship that would provide new enterprises a springboard to stability. It is observed that such entrepreneurial firms easily seize new business opportunities, become key players in the industrial sector and achieve high profit. This is applicable to both big enterprises and also small firms including start-ups. However, start-ups that are capable of utilizing innovation as an efficient tool may find it difficult to gain the advantages against bigger rivals due to their inexperience or incapability in innovation management/processes/tools, technology, human resources or incentives to implement innovation; or all (Quynh, 2016). This challenge can be easily addressed by becoming a part of a business incubation system.

\subsection{Techno Entrepreneurship Initiatives of ICAR}

ICAR institutionalized the concept of techno entrepreneurship through NAIF schemes and today novel agricultural ventures are created in large numbers and nurtured through appropriate interventions, incentives and investments. Through various programmes under the NAIF scheme, the institutional mechanism was reinforced to protect the innovations/IPRs generated and was able to transform Agribusiness Incubation ( $A B I$ ) centres as a hub for technology transfer and techno-entrepreneurship. The NAIF scheme contributed towards development of an IP environment in ICAR and all its institutes were empowered to handle technology management activities at the institute level itself and liaison with private clients for the commercial transfer of their technologies. The middle-tier of this mechanism consists of 10 subject-specific Zonal Technology Management Centres (ZTMC) for facilitating publicprivate partnerships. These zonal centres are entrusted with the promotion of technologies available at various institutes from their respective zones. The central IP and technology management mechanism is operational from the ICAR Headquarters, and it deals with the policy matters and techno-legal aspects that arise from various institutes (ICAR, 2019).

ICAR has set up a total of 50Agri-Business Incubators (ABI) in its various institutions during the past 10 years. Apart from these, many Technology Business Incubators (TBI), sponsored by the Department of Science and Technology (DST) are established at different State Agricultural Universities. As an institutional mechanism, independent units like Institute Technology Management Unit (ITMU) were constituted at each Institute, for better management and speedy process of IP protection, technology transfer and commercialization. ICAR also formed Agrinnovate India Ltd. (AgIn) as a "for profit" Company owned by Department of Agricultural Research \& Education (DARE), Ministry of Agriculture, Government of India, to act as an effective interface between ICAR, ZTMCS and ABI Centres on one side and the stakeholders of agricultural sector on the other side. (Figure 1). 


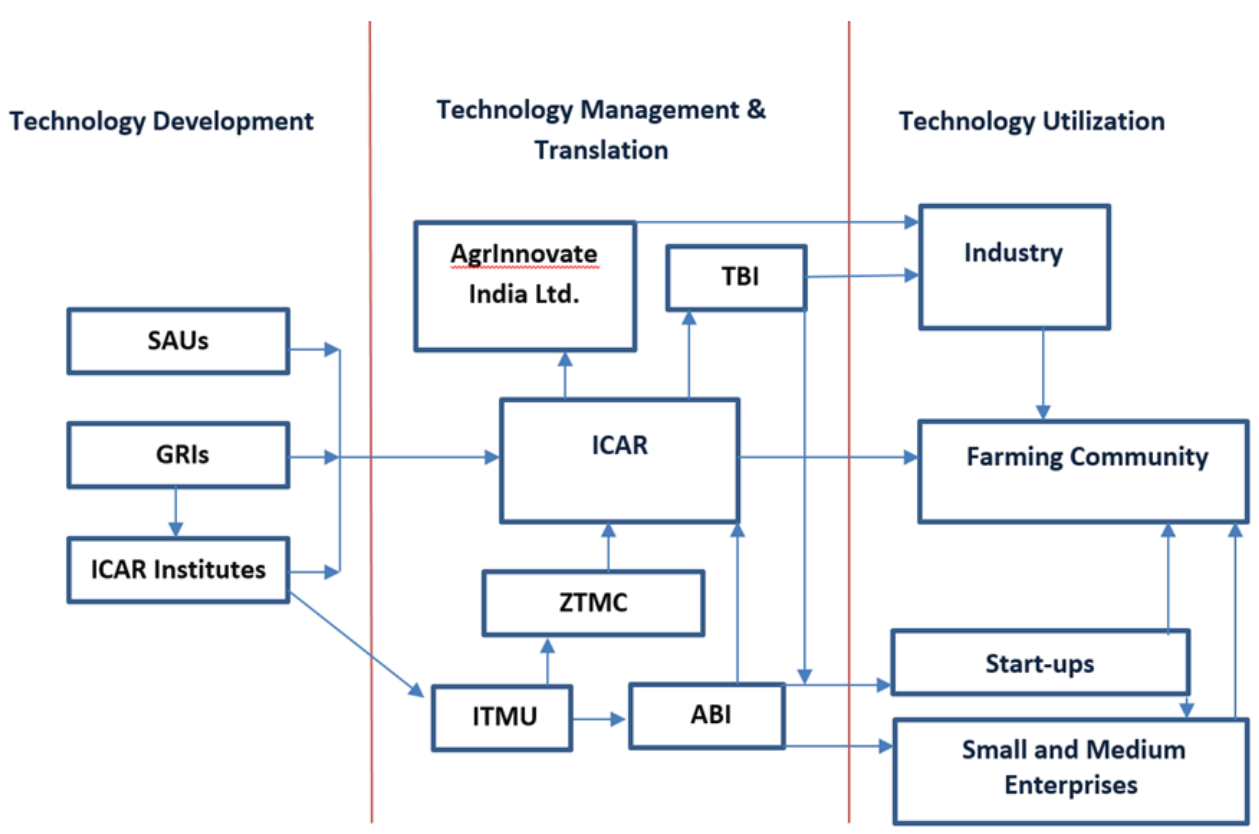

Figure 1: Institutional framework for Tech transfer and commercialisation

This framework provides the stakeholders easy access to the latest technologies/scientific know-how, and specialized training programmes for capacity building. Today ABI Centres under ICAR are recognized for their technology-led initiatives and speedy commercialization of innovations and research outputs. With their immense potential and state-of-the art facilities available, ABIs are improving the livelihoods of stakeholders in agri-production and consumption systems, even in rural regions. These Centres nurture the growth of new technology-based enterprises and also improve their survival rate by mustering support services like technology refining, validation, business strategy, planning, scale up operations, IP services, sourcing funds etc. that are essential for start-up firms.

\section{Technology Management in Fisheries Research}

\subsection{Business prospects in Indian Fisheries sector}

Fisheries and aquaculture, a sunshine sector in Indian agriculture is the prime source of income and employment generation for a large section of the economically backward population of the country, especially the fishermen community (Gol, 2019). The Indian fisheries sector contributes significantly to the food basket of the country, and has attained an annual production level of over six million tonnes of fish and shellfish, from marine and aquaculture sector. India is now the 2nd largest fish producing nation in the world and stimulates the growth of a significant number of supplementary industries. The total fish production is estimated to be 12.60 million metric ton during 2017-18 This constitutes around 6.3\% of the global fish production. From India, more than fifty types of fish and shellfish are exported to 75 countries around the world. Fish and fish products have become the largest group in agricultural exports from India, with 13.77 lakh ton, in terms of quantity and value. This contributes to $10 \%$ of the total exports and nearly $20 \%$ of the agricultural product exports, and contributes to about $0.91 \%$ of the GDP (NFDB, 2019). 


\subsection{Agri-Business Incubation Centre at ICAR-CIFT}

ICAR - Central Institute of Fisheries Technology (ICAR-CIFT) located at Kochi, Kerala state (India) started the $A B I$ Centre as a platform for empowering the fisheries sector by creating new technology-based industries. $\mathrm{ABI}$ Centre is functioning at a location with high fish production and vital markets, which makes it easily accessible to clients. It operates an important networking mechanism between R\&D institutes, private industry, government agencies, academia and funding agencies. This entrepreneurial support system caters to its clients through strong technical and advisory support, and assists them to orient their resources in the most optimized manner, thereby yielding high productivity and economic value (Mohamed, 2019). The Centre follows a facile technology dissemination procedure and it enables the entrepreneurs to explore new ways of doing business through a wide spectrum of activities. Proactive and value-added business services are provided to registered incubatees in the form of technology transfer, contract research, consultancy, contract service, office space, certified state-of-theart pilot level production facility, on-site guidance and specialized training to establish innovation-based business enterprises.

The Institute has developed a wide range of technologies pertaining to fishing technology, resource/ energy optimization, fish processing, value addition, high value by-products, packaging, customized processing equipment, health care products, aquaceuticals, etc. Some of the entrepreneur ready technologies developed by ICAR-CIFT are depicted in Table 1. These technologies are further classified according to their Technology Readiness Level (TRL).

Table 1: List of entrepreneur ready technologies developed by ICAR-CIFT

$\begin{array}{ll}\text { - } & \text { FARVEST } \\ \text { - } & \text { CIFT Turtle Excluder Device (CIFT-TED) } \\ \text { - } & \text { Fevice for Juvenile Fish Excluder cum Shrimp Sorting } \\ \text { - } & \text { Foldable Traps } \\ \text { - } & \text { CIFT- Muare Mesh Codend } \\ \text { - CIFT Semi-pelagic Trawl System (CIFT-SPTS) } \\ \text { - Large Mesh Purse Seine } \\ \text { - Short Body Shrimp Trawl } \\ \text { - Cut-away Top Belly Shrimp Trawl } \\ \text { - Treated Rubber Wood Canoe } \\ \text { - FRP Coated Rubber Wood Canoe } \\ \text { - Treated Coconut Wood Canoe } \\ \text { - CIFT Sun Boat } \\ \text { - Microencapsulated Sardine Oil } \\ \text { - Seaweed NutriDrink } \\ \text { - Ready-to-serve / Ready-to-cook food products } \\ \text { - Fish Kure - Extruded Product } \\ \text { - Seaweed and Fish Enriched Noodles } \\ \text { - Seaweed Enriched Cookies } \\ \text { - Value Added Products - Fish Sausage / Battered and Breaded }\end{array}$




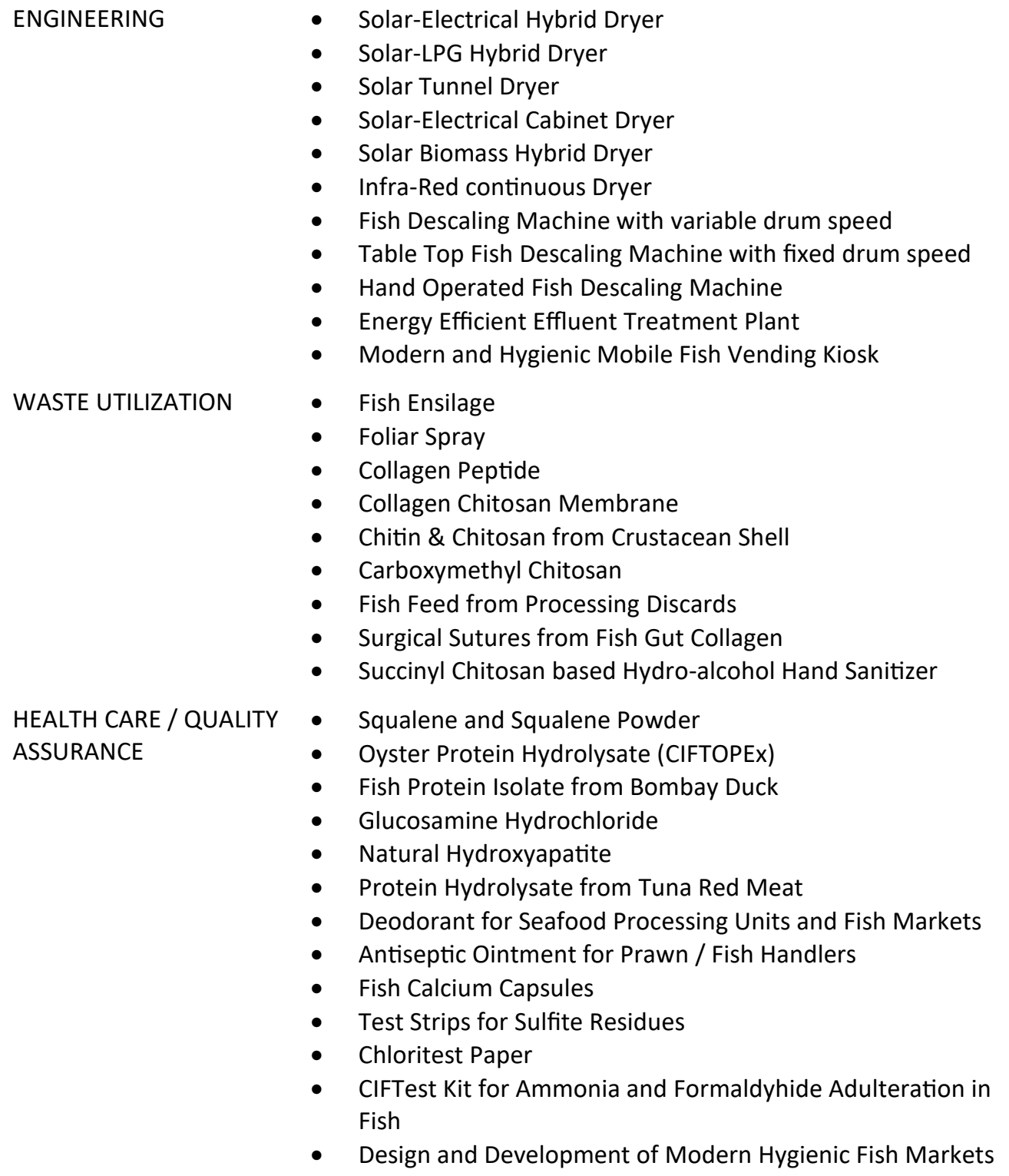

ICAR-CIFT allows start-ups as well as established business enterprises across the nation to register as incubatees at $\mathrm{ABI}$ Centre and get access to new innovations, cutting edge technologies and scientific know-how through direct as well as virtual incubation. The selective, comprehensive service offering and handholding accelerates the growth and sustenance of these incubatees. 


\subsection{Stages of Business Incubation}

The Centre possesses multi-tenant infrastructure facilities suitable to start a corporate level office for direct incubatees, within the premises of the Institute. Direct incubation is intended to handhold clients during their infancy period, where they can set up offices and production plants with no capital investment. Business Meets and industry-interface programmes are regularly conducted for sensitizing entrepreneurs, and identified candidates with viable business ideas are selected for incubation. The registered incubatees can meet scientists and business associates whenever required to discuss incorporating a business entity, understanding its legal aspects, product branding, intellectual property protection, finance management, market study, test marketing, etc. This ease of communication and networking helps in easy delivery of incubation services and guides the client to achieve successful outcomes. Incubatees are assisted in translating their idea to a technology and further to a market ready product or service. They can also select among the showcased technologies developed in the internal research laboratories and enter into a licensing deal.

Normally the residency period for direct incubatees is for one year, which may be extended on the basis of the nature of the business and progress of company development. As the start-up firms mature enough to operate a profitable business, the services and concessions provided are gradually withdrawn. The clients, apart from the registration fee to the Incubator, pay monthly payments for office space and pilot plant operations at a subsidized rate than the prevailing market rates. The business incubation center provides an array of services from idea stage to the product launch (Figure 2). After exiting from the incubator, incubatee mentoring is continued on need basis.

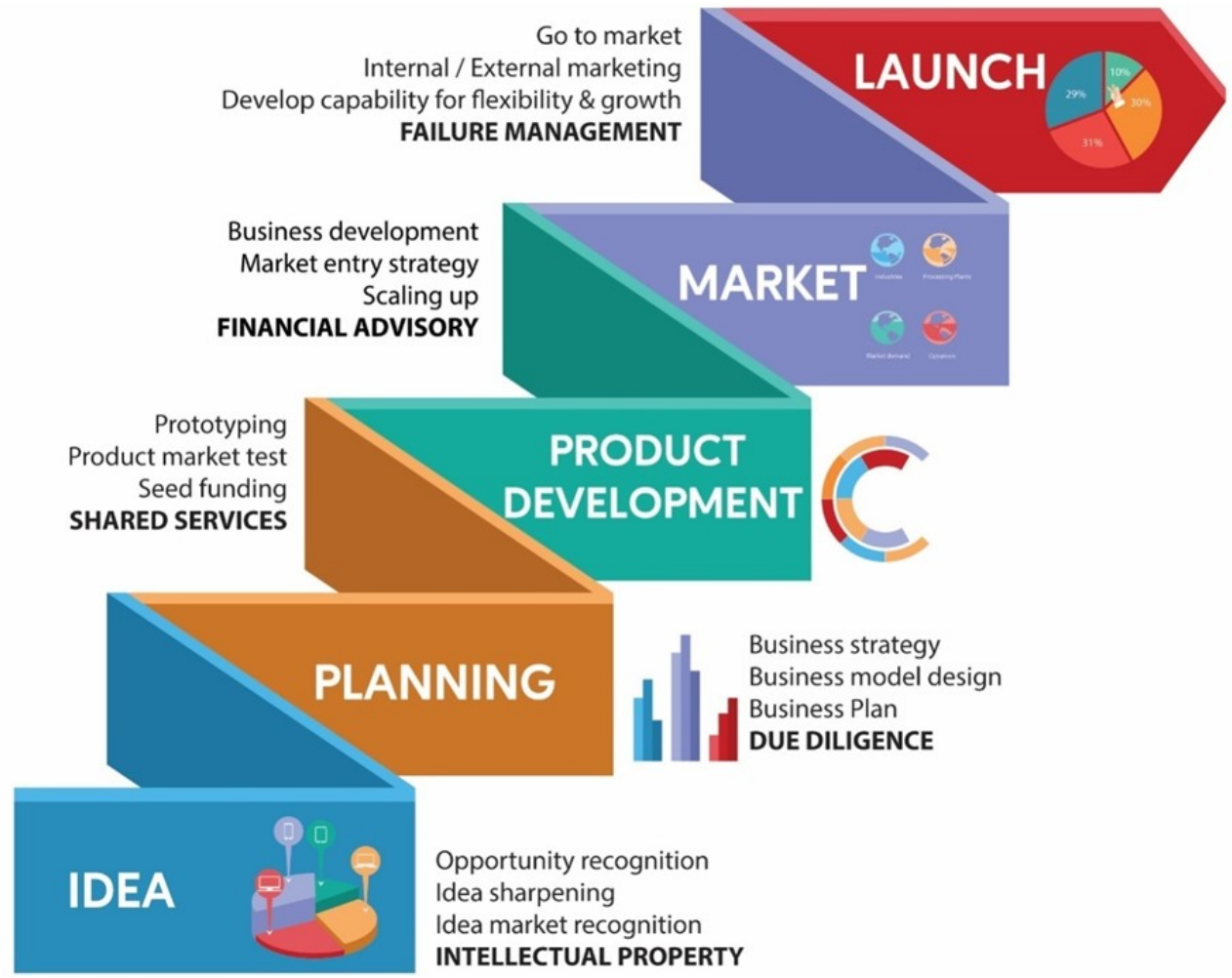

Figure 2: Techno-entrepreneurial support system of $A B I$ 


\subsection{Technology Readiness Level (TRL)}

Technology Readiness Assessments (TRAs) assumes importance in the incubation system, for the costeffective management of technologies and research results, and has become an essential entity to ensure the success of new initiatives in a field (ESA, 2008). It assists in the decision-making process regarding the adoption of novel technologies concepts, even during the absence of perfect outputs. Technology Readiness Levels (TRLS) are a method for estimating the maturity of technologies during the acquisition phase of a program, developed at NASA during the 1970s. The use of TRLs enables consistent, uniform discussions of technical maturity across different types of technology (Mihaly, 2017). This set of management metrics helps in the assessment of the maturity period of a particular technology within a specific system and operational environment.

$A B I$ Centre has devised a seven-point TRL scale to help the clients in decision making. This scale is developed on the basis of various categories of technology development stages and is very useful to clearly understand the project viability, maturity cycle and resource requirements. The TRL system calculates a technology's lifecycle, from Level 1 (Concept Evaluation) to level 7 (successful commercial application). The seven levels indicate a specific milestone in the concerned project where significant activities are performed (Figure 3). Most of the research and development projects pass through each of these seven levels until they are successfully integrated into the market, while some levels may not be applicable for certain technologies (Nolte, 2003). Each technology given in Table 1 is classified into various levels of TRL based on a few indicators and attributes (Table 2)

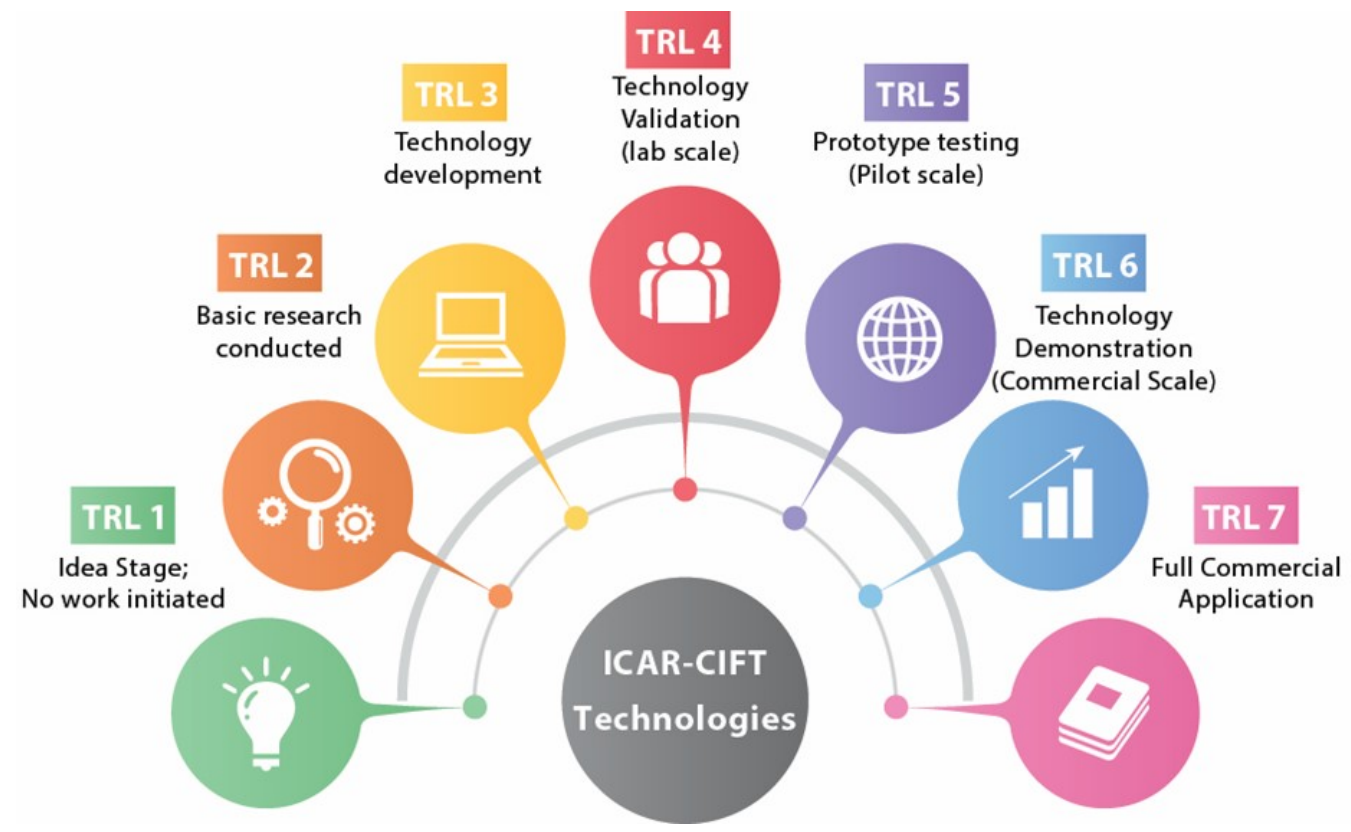

Figure 3: Categories of Technology Readiness Levels 
Table 2: Attributes for classification of TRL

\section{Technology Readiness \\ Level}

TRL 1: Idea Stage

TRL 2: Basic Research

TRL 3: Technology Development

TRL 4: Technology

Validation

TRL 5: Prototype testing

TRL 6: Technology

Demonstration
Activities

Valid concept, but unproven

Exploring the basic properties of a technology and translation of scientific results into applied research

R\&D work starts and technological solutions are developed

Integration of scientific principles, testing and validation of results in laboratory environment

Development of prototype in an operational environment and addressing the performance issues

Completion of testing phase and evaluation of technology performance under normal operating conditions

TRL 7: Full Commercial Application nology, in its final form, in industry

\section{Risk level Level of (Scale of 1-10; Competition from less to \\ high)}

10

8-9

7-8

5-6

4-5

1

10 scale conditions and real-time market

\subsection{Linking innovation to business development}

Public-private partnerships are the key factor that ensures the speedy and efficient commercialization of technologies. Increased rate of technology adoption by clients will in turn lead to increase in the production sector, farmers' income and employment (Mohamed, 2020). The key considerations for the process of technology transfer through commercialization are, national priorities relating to food security, sustainable use of natural resources, enhancing of farmers' income and employment generation. Translation process from innovation to business with respect to TRL is depicted in Figure 4. 


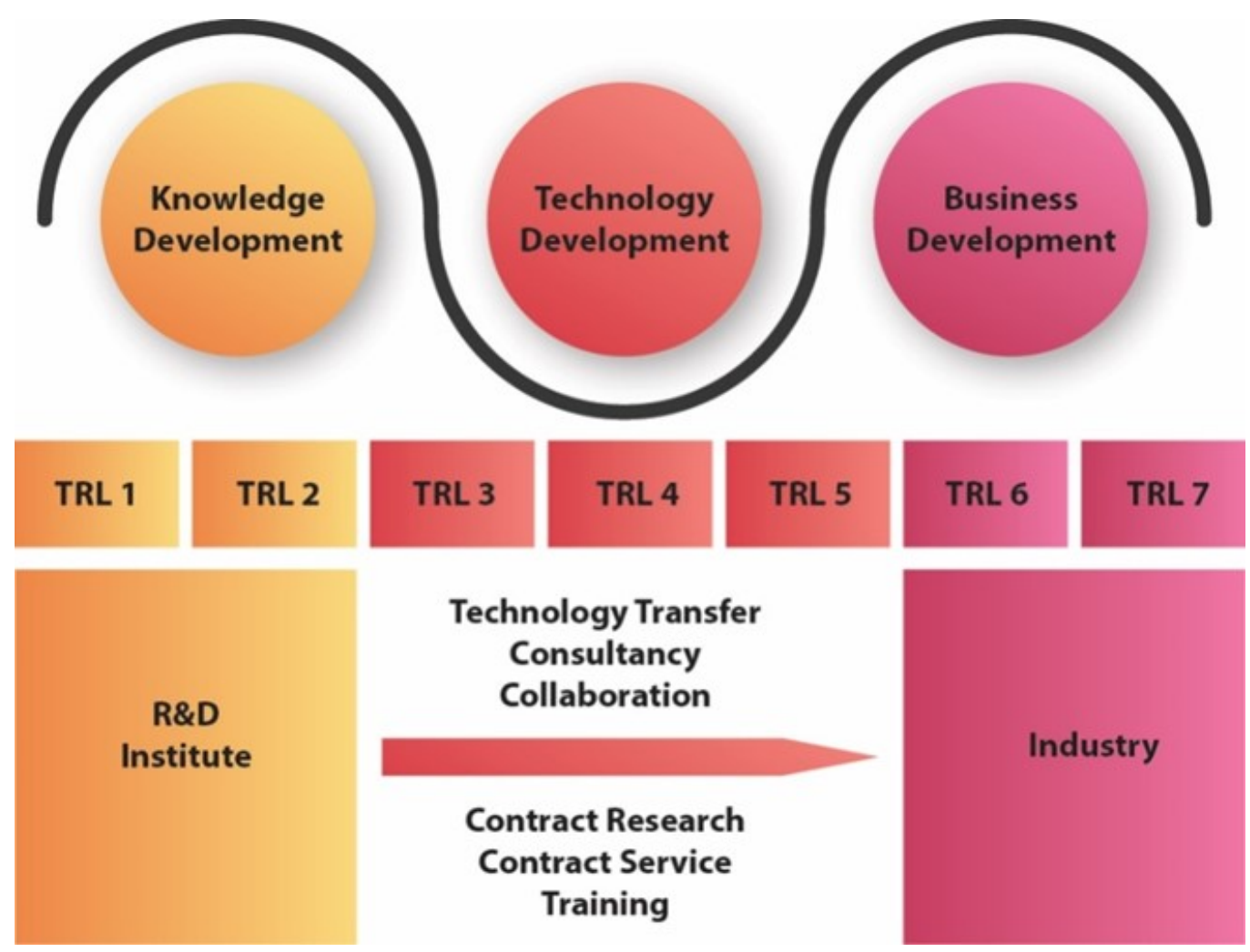

Figure 4: Transition from innovation to business

\subsection{De-risking technologies for successful commercialization}

Most of the time, the entrepreneurs find it difficult to up-scale the technologies, which are successful at laboratory level to industrial level. This is mainly due to the constraints with respect to the economies of scale, precision in process/protocols, management of big scale/sophisticated machineries/instruments, etc. To address this issue, ICAR-CIFT introduced a new concept of de-risking of technologies by using state-of-the art semi commercial pilot plant facilities set up as part of the incubation programme. By availing the facility, the incubatees can conduct trial production using larger machineries, with on-site guidance from ICAR-CIFT researchers. This helps the incubatees to accelerate their growth phase by launching their products, conduct test marketing and analyse the market behaviour even before establishing a production facility of their own. Once the product refinement and process optimization are completed successfully, incubatees can move out of the incubation support system. A flow chart combining mechanisms of technology development, management and commercialization is given in Figure 5. 


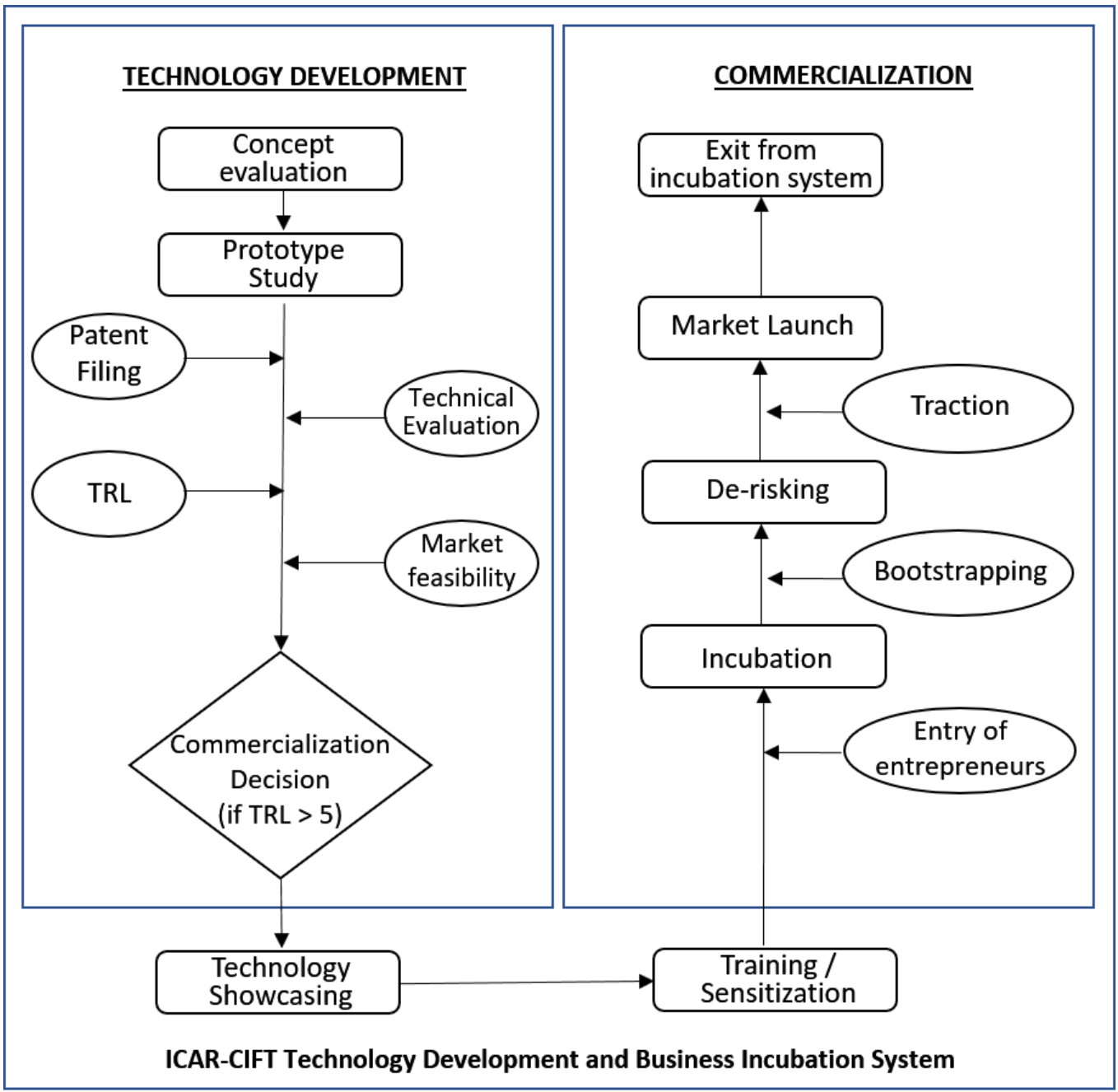

Figure 5: Mechanism of technology development, management and commercialization

\subsection{Case Study of ICAR-CIFT Solar Hybrid Dryer}

A case study of ICAR-CIFT Solar Hybrid Dryer, a successfully commercialized ICAR-CIFT technology showed the new institutional innovation in technology management and commercialization worked out well. Fishermen in India catch fish as a major aquatic product and it is intended mainly for domestic consumption and sale in the local market. However, in case of over catch, tremendous losses occur because the fishermen have neither access to markets in big cities nor to the international market. The sales are limited due to the perishable nature of the product and absence of a good marketing and distribution system. As an alternative, fishermen convert their catch into dried fishery products for additional benefits. Open air sun drying is the traditional method employed in India to dry fish and fishery products, infamous for higher microbial load and lower product quality. In this type of drying, fish is exposed in an open environment for direct sun light and natural wind for removal of moisture. But it often results in inferior quality of product due to its dependence on weather conditions and vulnerability to the attack of dust, rains, insects, pests, and microorganisms. Also, it requires longer drying time. 
To address the challenge, ICAR-CIFT has designed and developed various types of low cost, energy efficient and eco-friendly solar fish dryers. They include solar-electrical hybrid dryer, solar-LPG hybrid dryer, walk-in type solar tunnel dryer, solar-electrical cabinet dryer, solar-biomass hybrid dryer and Infra -Red continuous dryer. The capacity of these hybrid solar dryers varies $10 \mathrm{~kg}$ to $500 \mathrm{~kg}$ with 6 to $110 \mathrm{~m} 2$ of tray spreading area. Solar dryers offer numerous advantages over the traditional sun drying method, apart from being environmentally friendly and economically viable. In solar drying, a structure, often of very simple construction, is used to enhance the heating effect of the solar radiation. Compared to the sun drying, solar dryers can generate higher air temperatures and consequential lower relative humidity, which are conducive to improve drying rates and hence lower moisture content of the final products. Apart from fishes, this dryer is also suitable for drying other agricultural products like fruits, vegetables, spices and condiments. All of these dryers are provided with alternative heating sources in order to continue the drying process during off sunshine hours especially during night time, cloudy and rainy days.

The products made using solar dryers are found to be better in hygiene, colour, taste and other quality parameters, and thus get a longer shelf life period. Chances of outbreaks of fish-borne illnesses are very less, as appropriate hygienic practices are followed during handling, drying and transportation. Being a clean, green and affordable technology, many fishers and entrepreneurs have taken up dry fish production using solar hybrid dryers and were able to set up many profitable commercial ventures. This technology also minimizes the post-harvest losses to the fishers and ensures very good returns. The Technology Readiness Level (TRL) for various Dryer Models is given in Table 3. Most oCAR - Central Institute of Fisheries Technology (ICAR-CIFT) located at Kochi, Kerala state (India) started

Table 3: Technology Readiness Levels (TRL) for various Dryer Models

$\begin{array}{llr}\text { 1. } & \text { Solar Electrical hybrid dryer } & \mathrm{TRL}-7 \\ \text { 2. } & \text { Solar-LPG hybrid dryer } & \mathrm{TRL}-6 \\ \text { 3. } & \text { Solar Tunnel dryer } & \mathrm{TRL}-4 \\ \text { 4. } & \text { Solar-Electrical cabinet dryer } & \mathrm{TRL}-7 \\ \text { 5. } & \text { Solar Biomass hybrid dryer } & \mathrm{TRL}-3 \\ \text { 6. } & \text { Infra-Red continuous Dryer } & \mathrm{TRL}-2\end{array}$

During the period 2017-2020, 34 incubatees have registered in ABI Centre for product standardization and further hand holding for taking up solar dryer technology for dry fish production. Apart from this, during this period, 30 solar dryers have been commercialized through the incubation centre, and established at different places of India for the benefit of Entrepreneurs/Self Help Groups/Government Institutions. Out of the 30 Clients, 94\% people opted for technologies with TRL-7, considering its low risk (Table.2). However, some clients prefer to invest in technologies with TRL-4 or less by jointly developing, testing or customizing commercial level equipment. Though the risk is high, they prefer less competition and expect high return from a niche market. The number of incubates and entrepreneurs who adopted dryer technologies placed in various TRL levels (Table.3) are depicted in Figure 6. 


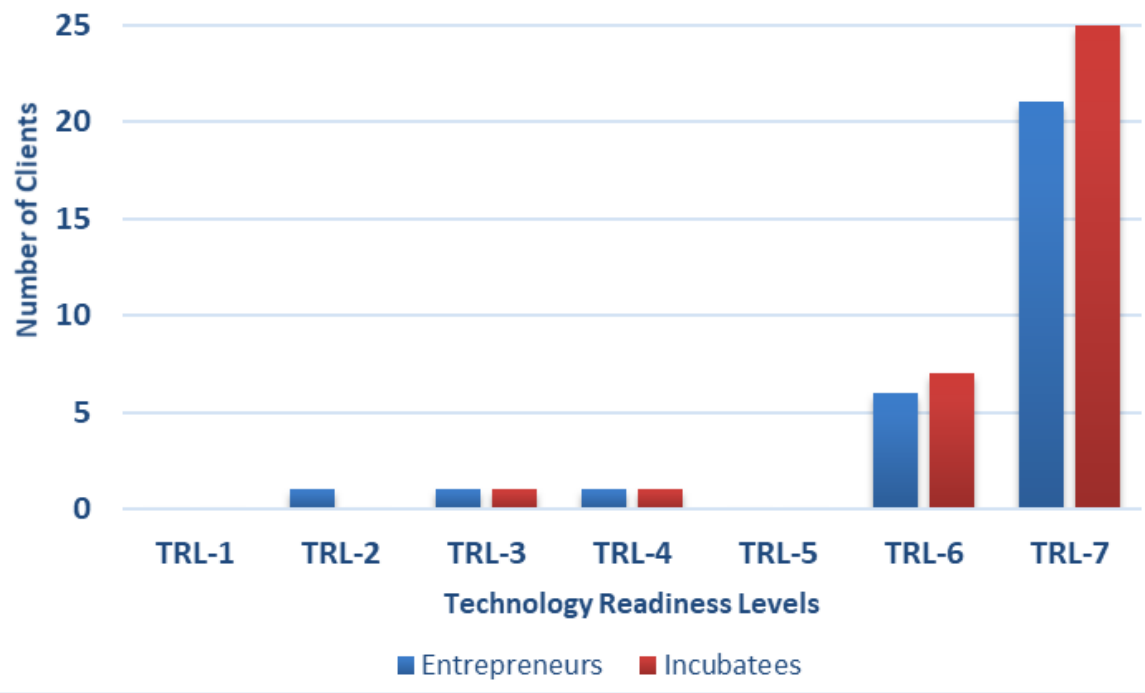

Figure 6: Adoption Pattern for Dryer Technologies

Nearly $30 \%$ of these incubatees adopted the technology after the incubation stage and set up their own production facilities. The Institute has identified and empaneled 10 manufacturing firms to assist the Incubatees for fabricating the dryers while setting up their own business ventures. The entire life cycle of Solar Hybrid Dryer Technology in an incubation system is depicted in Figure 7.
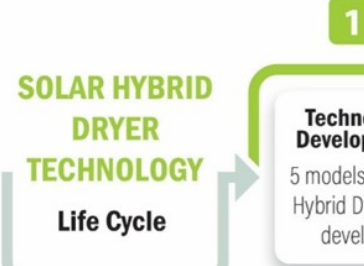
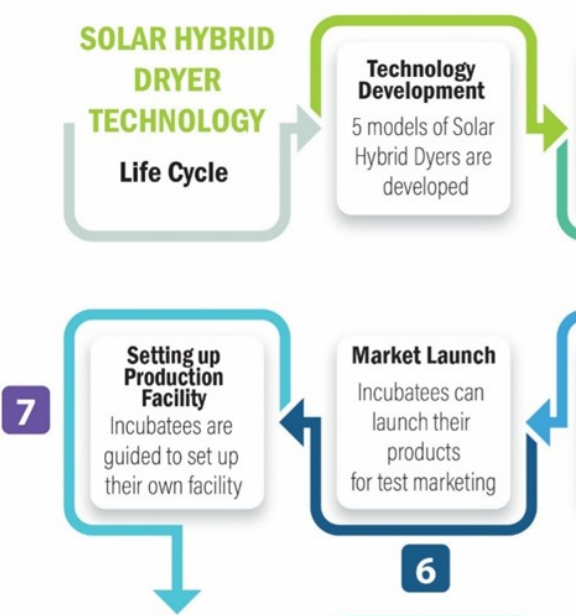

8

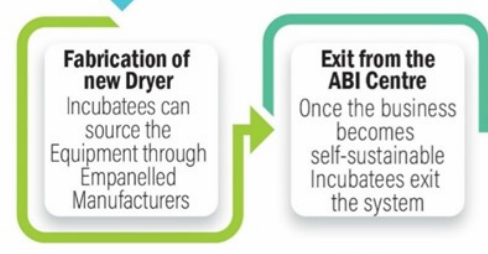

9

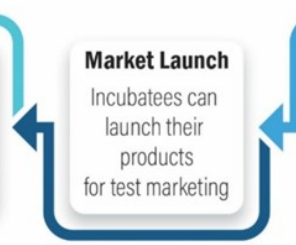

6
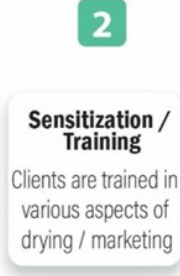

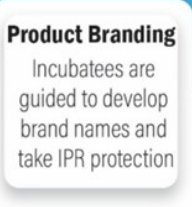

5

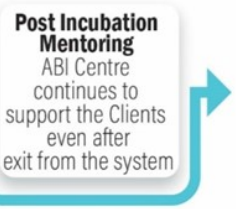

Incubatee Registration

Interested Clients can register at $A B \mid$

as Incubatees

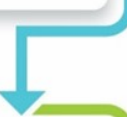

Trial Production

Incubatees can use

the Dryers \&

other machines

at Pilot Plant, on

shared basis
3

4

Figure 7: Life cycle of Solar Hybrid Dryer Technology in an incubation system 
A specific case study on Emma dry fish products, which is a micro dry fish business venture revealed that the technology is suitable for micro and small-scale entrepreneurs. Mr. Martin of Kumbalangi, Kochi, Kerala was one of the fishermen trainees who attended the two-day training program on pre-processing and drying of fish conducted during October 24-25, 2017 at ICAR-CIFT. In light of the knowledge about the energy and cost efficient solar drying technology perceived during the training period, he approached ICAR-CIFT with a determined plan to start a venture in hygienic dry fish business. As he was naïve in dry fish business and unaware of the dynamics of market, he initially registered as an incubatee of Agri-business incubation unit of ICAR-CIFT and started drying fish using ICAR-CIFT solar fish dryers established in the Pilot plant facility for de-risking purpose. Shrimp, mackerel, lizard fish, silver croaker, sole fish, glassy perchlet, anchovy, etc. were the common fishes dried by him. He did test marketing of the solar dried fish, packed in an attractive polythene package with ICAR-CIFT logo under the brand name "Emma Dry Fish Products" in the local markets and nearby super markets. The customer feedback and demands for these products made him realize the potential of dry fish business. After successful test marketing of solar dried fishes spanning for a period of more than six months, he procured a solarelectrical dryer of $20 \mathrm{~kg}$ capacity (TRL-7) from ICAR-CIFT empaneled manufacturing firm under the technical support of the Institute. He preferred a technology placed in TRL-7 bracket as his priority was on repayment of the loan taken towards capital costs without taking much risks. In November 2017, the dryer was commissioned and commercial production started (Figure 8). Now, Shri. Martin is serving hygienic and solar dried fish products under the brand name of "Emma Solar Dried Fish Food-Premium Quality" in 31 supermarkets of Ernakulam district (Figure 9). Recently, he entered into fresh fish marketing with the technical guidance of ICAR-CIFT.
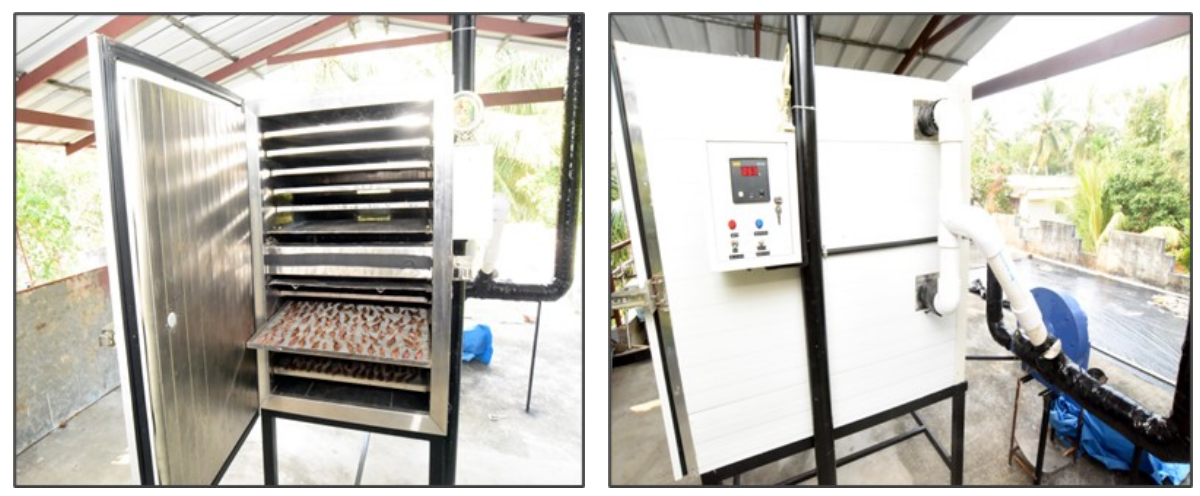

Figure 8: ICAR-CIFT-Solar dryer commissioned at Kumbalanghi, Ernakulam, Kerala

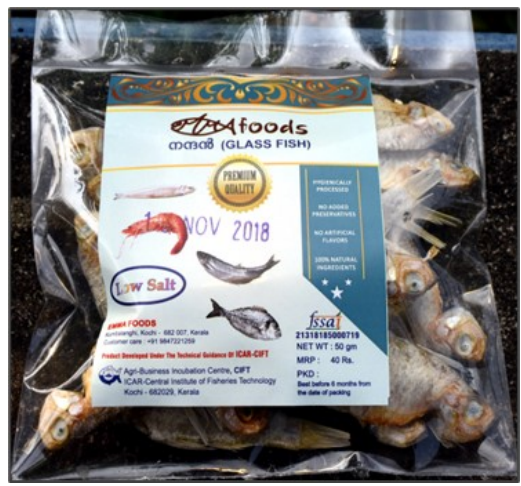

Figure 9: Emma Foods-A new venture in dry fish business under ICAR-CIFT technology support 
For this technology, all the financial viability criteria including B-C ratio, NPV and IRR were found to be positive. The fishermen turned entrepreneur normally takes up only a single batch drying in a day for effective utilization of solar energy resulting in reduction of operating expenses. He produces an average of 5-6 kgs of dry fish per day, considering $70-75 \%$ reduction in weight due to removal of moisture. Economic analysis showed that his average sale per day was about $\$ 42-\$ 50$ and their additional profit per $\mathrm{kg}$ of dry product ranged from $\$ 2$ - $\$ 3$. The Cost-Benefit analysis of the Solar-electrical dryer unit established by the entrepreneur is given below:

\begin{tabular}{ll} 
ASSUMPTIONS FOR CALCULATION: & \\
\hline Raw Fish Price & $-\$ 1.7 / \mathrm{kg}$ \\
Hygienically Dried Fish Selling Price & $-\$ 8.4 / \mathrm{kg}$ \\
Working Days & - Avg. 300 days \\
Investment on Fixed Assets & $-\$ 2,100$ \\
BENEFIT-COST ANALYSIS: & \\
\hline Expenses: & $-\$ 10,200$ \\
Working Capital for 300 days (@ 20 Kg/day) & $-\$ 200$ \\
Operating charges & $-\$ 252$ \\
Packaging and other miscellaneous charges & $-\$ 420$ \\
Interest on $\$ 2,800 @ 15 \%$ & $-\$ 210$ \\
Depreciation on Dryer 10\% & $-\$ 11,292$ \\
Total Costs & \\
Revenue: & $-1,800 \mathrm{~kg}$ of dry fish \\
Total Output for One Year (6000 kg x 30\% recovery) & $-\$ 15,120$ \\
Sales Return for One Year (\$8.4 per kg x 1800) & $-\$ 15,120$ \\
Total Revenue & $-\$ 3,828$ \\
Gross Annual Profit & $=1.34$ \\
B-C Ratio &
\end{tabular}

\section{Conclusion}

With the active participation and support from the Government of India, the country's R\&D institutes are catering to the entrepreneurial collective through incubation mechanisms. Public-private partnerships are happening in great numbers, thus manifesting advances with widespread technological innovation at a breakneck pace. The Indian Council of Agricultural Research (ICAR) with 50 business incubation centres across India, has proven to be a great platform boosting techno-entrepreneurship and nurturing innovation eco-system. The Agri-business incubation (ABI) Centre operational at ICARCentral Institute of Fisheries Technology has reached out to many clients including small and mediumsized technology-enabled enterprises and has helped to create a good number of jobs. The Centre provides value added business incubation and support services to help entrepreneurs, develop technology-based business ideas and establish sustainable enterprises. The innovative Technology Readiness Level (TRL) concept customized for the entrepreneurs helped in selecting the suitable technology by assessing its associated risks and returns. The ABI Centre has also successfully 
implemented the concept of 'de-risking' by providing pilot plant facilities for entrepreneurs to test the attributes of a marketable product/service produced using lab-tested technologies of the institute in an up-scaled production scenario. It also aids in subsequent test marketing and economic viability analyses.

A case study was conducted on a successful fisherman who turned into a micro-level dry fish businessman by adopting the TRL-7 technology of Solar-electrical hybrid fish dryer. He used the derisking facility provided by the Institute, and successfully conducted test marketing for a period of more than six months before investing on the dryer technology. The cost-benefit analysis showed a B-C ratio of 1.34 for the adopted technology and it was observed that his average sale per day was about $\$ 42-$ $\$ 50$ with an additional profit of $\$ 2$ - \$3 per kg of dry product. The ABI Centre focuses on developing techno-entrepreneurship by linking public sector resources and private sector business initiatives within and across regional and national boundaries. This initiative is expected to sensitize the farmers, fishers and entrepreneurs on creating improved value chains of their products, guide and handhold them towards the same by adopting novel and affordable technologies, and ultimately fetch more profit and create more employment and livelihood opportunities.

\section{References:}

European Space Agency (ESA). (2008). Technology Readiness Levels Handbook for Space Applications, Issue 1 revision 6, TEC-SHS/5551/MG/ap. Paris: European Space Agency.

Food and Agricultural Organization (FAO). (2019, July 27). India at a glance [Web page]. Retrieved from www.fao.org/india/fao-in-india/india-at-a-glance/en

Government of India (Gol). (2018). Handbook on Fisheries Statistics. Department of Fisheries, Ministry of Fisheries, Animal Husbandry \& Dairying Government of India, New Delhi, India.

Indian Council of Agricultural Research (ICAR). (2006). ICAR Guidelines for Intellectual Property Management, Technology Transfer and Commercialization. Indian Council of Agricultural Research, New Delhi, India.

Indian Council of Agricultural Research (ICAR). (2014). ICAR Rules and Guidelines for Professional Service Functions. Indian Council of Agricultural Research, New Delhi

Indian Council of Agricultural Research (ICAR). (2018). ICAR Guidelines for Intellectual Property Management and Technology Transfer/Commercialization. Indian Council of Agricultural Research, New Delhi.

Indian Council of Agricultural Research (ICAR). (2019, August 1). Intellectual Property and Technology management unit [Web page]. Retrieved from www. icar.org.in/node/131

Indian Chamber of Food and Agriculture (ICFA). (2019, July 26). All India Agri start-up. [Web page]. Retrieved from www.icfa.org.in/assets/doc/reports/all-india-agri-startup-convention-2018.pdf

Mihaly, H. (2017). From NASA to EU: The evolution of the TRL scale in Public Sector Innovation. The Innovation Journal, 22: 1-23.

Mohamed, R.A., Samuel, M.P., Ninan, G. \& Ravishankar, C.N. (2020) Accelerating Entrepreneurship Development in Fisheries Sector through Agribusiness Incubation. Indian Farming, 70(1), 3-7.

Mohamed, R.A., Ninan, G. \& Ravishankar, C.N. (2019). Technology backstopping to promote start-up ecosystem in India - a case study. pp. 1-9 In S. Ayyappan, Mukund A.K., Letha Devi G. (eds), Agristart-ups for smart farming. New Delhi, India: International Books \& Periodical Supply Service. 
National Academy of Agricultural Research Management (NAARM). (2019, July 25). Agri Business Incubator of NAARM (NAARM-ABI) [Web page]. Retrieved from https://naarm.org.in/agri-businessincubator-of-naarm-naarm-abi/

National Fisheries Development Board (NFDB). (2019, August 1). About Indian Fisheries [Web page]. Retrieved from http://www.nfdb.gov.in/about-indian-fisheries

Nolte, William L., Kennedy, Brian C. \& Dziegiel, Roger J. (2003). Technology Readiness Level Calculator. Technology Readiness Level Calculator. Proceeding of NDIA 6th Annual Systems Engineering Conference October 20-23, 2003, San Diego, CA, USA. San Diego, USA: National Defense Industrial Association.

National Skill Development Corporation (NSDC). (2020). Skilling India Empowering Lives. New Delhi, India. Retrieved from https://nsdcindia.org/sites/default/files/PMKVY ebook english-April18 0.pdf

OECD/ICRIER. (2018, July 26). Agricultural Policies in India, OECD Food and Agricultural Reviews. Paris: OECD Publishing.

Quynh, P.M. (2016). Promoting Innovation for Start-ups- Summary Report. Ha Noi, Vietnam: APEC Small and Medium Enterprises Working Group.

Srinivas, K., Gerard, M., Singh, V., Gupta, M., Soam, S.K., Arunachalam, A., Datt, S., Saxena, S. \& Srinivasa Rao, Ch. (2018). Agri-Start-ups: Reflection of ICAR Technologies in Market. New Delhi: Indian Council of Agricultural Research. 